\title{
INFORMÁTICA NA EDUCAÇÃO: VANTAGENS E EMPECILHOS
}

\section{COMPUTER SCIENCE IN EDUCATION: ADVANTAGES AND DIFFICULTIES}

\author{
Cristine Isabel SIMÃO* \\ Mariná Holzmann RIBAS ${ }^{* *}$
}

\begin{abstract}
Resumo: Adentramos o século XXI com a certeza de que o conhecimento será a principal fonte de riqueza do homem, cercada pelas altas tecnologias de informação e comunicação. Não poderíamos deixar de dizer que as tecnologias, dentre elas o computador, chegaram à educação, mesmo que ainda de forma suave. O presente trabalho relata uma investigação sobre as vantagens e os empecilhos do uso do computador na educação, verificando que, apesar de a jornada da informática na educação não ser insipiente, há muito que fazer. $\mathrm{O}$ trabalho nos aponta outro viés pelo qual a informática na educação deverá ter suas atenções redobradas, que é a formação do professor, uma formação que precisa despontar para novos caminhos de uso pedagógico do computador, num processo de mudanças de paradigmas, rompendo barreiras. As experiências realizadas e relatadas pelos professores neste trabalho nos dão a esperança de que os diferentes usos do computador na educação possam vir a ser uma ferramenta poderosa à disposição dos professores, porque as vantagens do seu uso são imensas. As experiências se mostram favoráveis, mesmo diante de inúmeras dificuldades, e o desejo de mudar está dentro de cada um desses profissionais, que buscam incansavelmente novas formas de ensinar e também de aprender, dando vida à educação. Diante da realidade
\end{abstract}

\footnotetext{
* Pedagoga. Mestre em Educação pela UEPG. Professora da Faculdade de Telêmaco Borba. E-mail: cisimao@hotmail.com

${ }^{* *}$ Pedagoga. Mestre e Doutora em Educação (Supervisão; Currículo) pela PUC-SP. E-mail: mhribas@uol.com.br
} 
Informática na educação: vantagens e empecilhos

relatada, alguns caminhos podem ser apontados como possíveis mudanças, com a finalidade de contribuir para que a informática na educação tenha um lugar de destaque dentro das nossas escolas públicas.

Palavras-chave: Formação de professores. Tecnologia. Informática na educação.

Abstract: We start the $21^{\text {st }}$ century aware that knowledge will be the main source of wealth for men surrounded by high technologies of information and communication. It is necessary to mention that technology, including computers, is part of education nowadays even though still in a superficial form. The present paper reports an investigation about the advantages and difficulties of using computers in education; the paper also points out that there is still a lot to do concerning the use of computers in education. The investigation demonstrates that in order to use information technology in a useful way in education teacher education needs to change paradigms and break barriers and prepare teachers for the use of computers in their teaching practice. The experiences developed as well as teachers' reports demonstrate that the different uses of computers in education can become a powerful tool for teachers as there are numerous advantages. Despite the various difficulties the experiences show that teachers are willing to incorporate the new technologies in their teaching as they look for news forms of teaching and learning in order to give education a new impetus. The reality reported points out paths that can lead to change that can contribute so that information technology in education has a central role in public schools.

Keywords: Teacher education. Technology. Computer science in education.

A tecnologia vem provocando diversas mudanças no mundo, influenciando cada vez mais nossa vida e nossa maneira de pensar e de agir. Vivemos hoje em uma sociedade marcada pelo desenvolvimento 
da informação e da comunicação, viabilizada por altas tecnologias. No centro dessa revolução, encontramos o computador, utilizado nas mais diversas áreas, inclusive na educação, não apenas para processar informações, mas, sobretudo como meio de comunicação.

O computador chega à educação lançando novos desafios, exigindo novas funções. Ele representa uma transformação ampla, que vai além do processo de ensino e aprendizagem, preparando os cidadãos de forma plena para viver no novo milênio, comunicando-se com o mundo e assumindo o comando de suas vidas. Enfim, participando de forma ativa e efetiva na sociedade.

Desde a chegada da informática na educação brasileira, muitas barreiras foram vencidas, alguns anos de experiências, pesquisas e projetos reuniram boa bagagem, permitindo o suporte necessário para que os computadores se integrassem ao cotidiano das escolas do sistema público de ensino.

Cremos, porém, que outras batalhas precisam ser vencidas. Alguns mitos precisam ser desfeitos, principalmente aquele que insiste em anunciar a substituição do professor pela máquina, e algumas meias verdades acerca do uso do computador precisam ser esclarecidas. Isso porque elas podem servir de instrumento de dominação. É necessária uma atualização constante das formas de utilização do computador como ferramenta pedagógica, explorando sua real contribuição para a construção do conhecimento.

Essa atualização só ocorrerá quando houver práticas suficientes, isto é, quando os professores se aliarem ao computador (perderem seus medos) e acreditarem nas possibilidades e contribuições que essa ferramenta pode fornecer para a educação. As tecnologias disponibilizadas pelo computador já estão presentes no cotidiano de nossas escolas, através de nossos alunos. Fazem parte do seu conjunto de atividades. Nossos alunos já nasceram acostumados com essa cultura tecnológica, cercada pelos vídeos, pela televisão, computadores e outros equipamentos eletrônicos. Não sentem qualquer dificuldade com os inúmeros termos técnicos e botões. Muito menos nesse contexto de rapidez da informação e de mudanças. Eles não têm medo de arriscar.

É preciso, portanto, estimular os professores a repensarem suas práticas. Sabemos que toda mudança é caracterizada por duas atitudes: de um lado, os que são favoráveis, e de outro, aqueles que resistem. Estes têm total aversão ao desconhecido. Não gostam nem de falar em alterações curriculares. Render-se à multimídia e a telemática, nem pensar. 
Informática na educação: vantagens e empecilhos

\section{FORMAÇÃO DE PROFESSORES}

O contexto histórico atual exige que o professor esteja aberto a mudanças, dispondo-se a modificar sua prática. Ele precisa acompanhar atentamente o surgimento de recursos inovadores. No entanto, é difícil convencê-lo sobre a necessidade da utilização desses recursos quando não há capacitação adequada. Não dá simplesmente para exigir que os professores utilizem esses recursos apenas para justificar sua prática em sintonia com a modernidade, sem a adequação a necessidades reais.

Essa tarefa não é fácil. A formação dos professores é ainda fortemente alicerçada no paradigma positivista, em que há a fragmentação do conhecimento e a dicotomia entre teoria e prática. Muitas mudanças precisam ocorrer nos cursos de formação.

Enquanto as instituições formadoras insistirem neste paradigma, a atuação do professor continuará prejudicada, pois ele enfrenta situações problemáticas e complexas em seu campo de trabalho. A formação profissional persistirá sustentada por um modelo inadequado, que não considera as competências práticas e dificulta o desenvolvimento de capacidades dirigidas para aspectos mais humanizantes e criativos das pessoas.

Para consolidar a educação nos dias atuais, se realmente queremos uma escola competente para um ensino crítico, criativo, de qualidade, que desenvolva o cidadão, precisamos adotar outros parâmetros para permitir que o professor desenvolva habilidades de formador e estimulador do pensamento e da inteligência do aluno. Segundo Demo (1992, p. 36), é urgente desenvolver habilidades como:

[...] a capacidade propedêutica, definida como competência em construir condições adequadas do aprender a aprender, do saber pensar, de pesquisar, de teorizar a prática, de atualizar-se constantemente. Trata-se de habilidade tipicamente metodológicoinstrumental, de domínio de meios e métodos, para ele poder produzir conhecimento com a devida destreza, capacitando-se, assim a construir com a criança o mesmo ambiente produtivo, construtivo, participativo.

Apesar de exigir muito, apenas a capacidade propedêutica não é suficiente. Segundo o mesmo autor, urge "dominar conteúdos". É preciso saber "filosofia, matemática e conhecer muito a própria língua". É 
necessária também a "instrumentalização eletrônica", cada vez mais importante na construção e socialização do conhecimento. A informática é relevante porque propicia condições para melhor produzir e manejar o conhecimento. Por fim, tendo em vista um princípio científico e educativo, o professor deve dedicar-se à pesquisa, para conseguir uma atitude crítica e criativa no trabalho, capaz de fazer convergir os verbos "saber" e mudar".

O ideal seria que o educador aprendesse a lidar com as tecnologias durante sua formação inicial, nos cursos de Licenciatura e de Pedagogia, porque isso facilitaria a sua ação na prática, no uso desse novo referencial pedagógico, nas atividades práticas. Atitude importante para o educador é "saber integrar conscientemente o uso do computador na prática pedagógica, transformá-la e torná-la transformadora do processo de ensino e aprendizagem". (MEC, 1998, p. 10).

Todavia, é importante que o professor se conscientize de que não se muda de

paradigma educacional apenas colocando uma nova roupagem, camuflando velhas teorias, pintando fachada da escola, colocando telas e telóes na sala de aula, se o aluno continua na posição de mero expectador, de simples receptor, presenciador e copiador, e se os recursos tecnológicos pouco fazem para ampliar a cognição humana. (MORAES, 1997, p. 17).

A palavra de ordem é mudar. Mas mudar o quê? A educação encontra-se num período de transição, vivenciando crises e buscando possíveis soluções, para transpor obstáculos e alcançar o mínimo exigido por uma sociedade em constante mudança.

Sendo assim, cabem alguns questionamentos: Como ensinar na era da informação? Quais as vantagens que as tecnologias, principalmente o computador, têm a oferecer à educação? Como fica o papel da escola, do professor, do aluno nessa sociedade caracterizada pela informação e pelo conhecimento extramuros da escola?

Ao analisar historicamente os caminhos da educação, percebemos que as mudanças na área sempre foram morosas. A tecnologia está nesse ambiente apesar de não ter sido produzida exclusivamente para o educacional. Esse fato contribuiu para ela fosse desacreditada em sua real contribuição para a educação. Torna-se necessário salientar tais trajetórias morosas deixaram algumas marcas, o que

resultou na existência, entre muitos educadores, de um senti- 
Informática na educação: vantagens e empecilhos

mento de descrédito em relação ao uso de artefatos tecnológicos no processo de ensino. Esta "repulsa" só pode ser compreendida e superada à medida que, além de conhecermos sua origem, apontemos para uma nova compreensão da importância do uso da tecnologia educacional no processo ensino-aprendizagem. (OLIVEIRA, 1997, p. 9).

O assunto tecnologia não se esgota quando se trata de sua aplicabilidade na educação. É algo que vem sendo discutido há muito tempo, gerando posicionamentos a favor e contra a sua utilização, mas Belloni (1999, p. 53) lembra que toda tecnologia, em qualquer situação do processo ensino-aprendizagem, deve vir acompanhada da reflexão sobre o que realmente existe por trás dela; não devemos esquecer que ela é o meio e não um fim em si mesma, nosso fim é a educação, o desenvolvimento de nossos alunos, e é isso que não podemos perder de vista.

\section{DIFERENTES USOS DO COMPUTADOR NO ENSINO}

A chegada do computador na sala de aula gerou e ainda gera nos professores muitas inquietações, dúvidas e ansiedades. Cremos que, antes do uso dessa tecnologia, é necessário quebrar barreiras, destruir as muralhas da resistência às mudanças exigidas, principalmente vencer a mitificação em relação ao computador, tido como algo mágico, capaz de trazer soluções milagrosas para a educação, uma supermáquina, diabólica, que faz tudo, uma presença de destaque no ensino, podendo até substituir o professor.

É importante ressaltar que as tecnologias da informação e comunicação permitem um reencantamento na escola. Portanto, não há mais como negar a importância desses recursos na educação, vislumbrando um futuro na sociedade do conhecimento. A presença plena da informática na educação é inevitável.

As tecnologias na educação não trazem soluções imediatas, mas viabilizam novas formas de apreensão do conhecimento, e elas "permitem ampliar o conceito de aula, de espaço e tempo, de comunicação audiovisual, e estabelecer pontes novas entre o presencial e o virtual, entre o estar juntos e o estarmos conectados a distância". (MORAN, 2000, p. 12). Promovem mudanças significativas na maneira como enxergamos o mundo, de como agimos sobre ele.

As tecnologias precisam ser vistas como mais do que circulações 
de informações. Precisam ser consideradas como ferramentas pedagógicas, entendidas como algo a mais a serviço dos objetivos educacionais, contribuindo para a melhoria do processo ensino-aprendizagem.

Por outro lado, de nada adiantarão recursos dos mais modernos e sofisticados se eles não passarem de meros entulhos em algum canto da escola, ou até mesmo se eles permanecerem fechados em suas embalagens, à espera de instalações que nunca são realizadas.

As tecnologias trazem desafios e promovem novas interações, sejam elas aluno-professor, aluno-aluno, aluno-máquina, professormáquina ou professor-professor. Essas relações criam situações jamais vividas, modificando, portanto, todos os papéis na escola. Novos conhecimentos e novas linguagens vão surgindo no cotidiano dos nossos alunos. São novidades atrás de novidades. O contato com o mundo, com a atualidade praticamente imediata é sem dúvida o grande fascínio dessas tecnologias, que já fazem parte de todas as áreas, do cotidiano de muitas pessoas, e agora, mais conscientemente, da educação.

Por isso, é preciso que nos cursos de formação não seja ensinado apenas o domínio do computador, mas sim, que ocorra uma integração entre as teorias educacionais que darão suporte às suas aplicações pedagógicas, às habilidades e à tecnologia, dando condições para o professor desenvolver atitudes críticas e reflexivas acerca dos aplicativos dos programas, dos softwares a serem usados. Os professores precisam conhecê-los a fundo, analisá-los, dimensionando a sua real importância e verificando se eles propiciam uma mudança efetiva, contribuindo para a construção do conhecimento do aluno.

Que os professores se apropriem do computador de uma forma que permita que eles possam incorporá-lo na sua prática, com seus alunos, sempre levando a refletir sobre o seu papel.

\section{INFORMÁTICA NA EDUCAÇÃO: EXPERIÊNCIAS VIVIDAS}

Foi partindo dessas questões que nos propusemos a realizar este trabalho. O primeiro interesse na pesquisa era analisar como os softwares educacionais poderiam ajudar as crianças com dificuldades de aprendizagem. A idéia inicial foi abandonada quando percebemos que outras questões estavam implícitas nessa primeira proposta.

Propusemo-nos então a investigar quais as vantagens, os empecilhos e as dificuldades enfrentadas no uso do computador, para que pudéssemos colaborar com dados reais para reorientação do próprio 
núcleo de tecnologia, colaborando também para a desmistificação do uso da informática, principalmente quanto aos empecilhos.

Os dados da pesquisa foram obtidos por meio de questionários e entrevistas com professores da rede pública estadual de Ponta Grossa com o seguinte perfil:

a) professores que participaram de cursos realizados pelo Núcleo de Tecnologia Educacional em 2001 e 2002;

b) professores que realizaram ou que estivessem realizando um projeto na sua escola envolvendo os recursos da informática.

Os questionários trouxeram informações importantes a respeito de como os sujeitos da pesquisa vêm utilizando a informática. As perguntas foram quase todas abertas, para que os professores pudessem relatar as experiências ocorridas nas suas escolas.

Os questionários foram entregues em mãos a cada professor. Foi marcada uma data para a devolução, mas nem todos os professores fizeram a devolução. Desta forma, foram distribuídos 28 questionários, em 10 escolas, 18 dos quais foram respondidos. Ressaltamos que seis das dez escolas têm laboratório de informática com dez computadores, em média, e quatro delas não contam com nenhum computador à disposição dos professores e alunos.

As entrevistas foram realizadas com seis professores, em quatro escolas públicas estaduais. Três professores tinham respondido o questionário e três não. O objetivo da entrevista foi de complementar os dados obtidos com o questionário, visto que os professores entrevistados realizaram ou estão realizando algum projeto nas suas respectivas escolas. Eles têm grandes contribuições no sentido de mostrar o que é possível fazer, mesmo com um número pequeno de computadores. Todas as entrevistas foram realizadas em datas e locais marcados pelos próprios professores. Elas se desenvolveram naturalmente e foram todas gravadas e transcritas fielmente.

Os questionários e as entrevistas se complementam entre si. Ambos tiveram suas respectivas relevâncias. Baseando-nos no depoimento dos professores, pudemos ressaltar os seguintes pontos: a aceitação do computador em geral é boa por parte dos professores e existe uma expectativa muito grande, gerando um verdadeiro caso de amor e ódio ao mesmo tempo, pois ao mesmo tempo em que gostam, sentemse receosos. Eis alguns depoimentos:

A aceitação é boa por parte dos professores, que pensam em utili- 
zar o computador como uma ferramenta de apoio em suas aulas. Foi com satisfação a chegada dos computadores na escola. No início, os professores ficavam se perguntando como que deveria ser trabalhado com os alunos. Alguns professores logo foram manipulando o microcomputador, mas a maioria sentiu dificuldade. Logo não dominavam este equipamento. Eu, particularmente, gostei muito. Minha disciplina tinha a ver com o microcomputador, haja vista que na grade curricular da escola consta a disciplina de informática (optativa) no ensino médio e no ensino fundamental.

A rejeição: a própria palavra já diz do receio do novo, do medo de estragar, com muitas cobranças, e o mito em relação à máquina:

Ficam contentes por saber que haverá mais esta ferramenta didática. Mas logo ficam receosos se haverá cobrança ou obrigatoriedade de utilizá-lo, pois a maior parte dos professores não tem conhecimento ou então, sentem-se inseguros para levar seus alunos até o laboratório de informática. Isto também se deve ao fato de que os professores não teriam o que rodar nos micros.

A utilização: muito poucos professores utilizam o computador, ainda que de forma rara, em alguns projetos.

Utilizo os computadores esporadicamente porque o número de micros é muito reduzido, as turmas são aproximadamente de 40 alunos por turma e há outros professores que também os usam, o nosso colégio tem um número muito grande de professores e alunos.

Apenas em um projeto interdisciplinar, por algumas vezes. Não teria também o que passar dentro de minha matéria. Eu poderia passar alguns assuntos, mas precisaria de uma pessoa para auxiliar no funcionamento das máquinas e da rede, para que daí como professor da disciplina, pudesse acompanhá-los no aprendizado.

Quanto às dificuldades apresentadas por eles, a principal está em não saber o que fazer com o computador, além da falta de um laboratorista, do número insuficiente de máquinas em relação ao número de alunos, mas a maior de todas é a falta de laboratórios em muitas escolas: 
Informática na educação: vantagens e empecilhos

A maior dificuldade é sem dúvida a falta de equilíbrio entre o número de alunos e o número de computadores. As turmas têm em média 40 alunos, e os laboratórios dez máquinas. Fica praticamente impossível desenvolver um trabalho com boa qualidade $e$ sem desperdício de tempo. Além de ser muito desgastante para o professor, que precisa dividir a turma, deixando uma atividade para os que ficam em sala de aula, e trabalhando com os que vão ao laboratório, sendo ainda necessário que dê conta de atender de todos, os que ficam e os que vão.

Já quanto às vantagens, eles percebem que o uso do computador provoca nos alunos maior motivação, os alunos gostam, muda a rotina de sala de aula, tanto de alunos quanto dos próprios professores:

A informática está presente em nosso cotidiano. É impossível não inserir na educação, sob o risco de a escola ficar cada vez mais distante dos avanços tecnológicos. As vantagens são tornar as aulas mais interessantes, atrativas aos alunos, que, ao mesmo tempo em que aprendem o conteúdo, também se familiarizam com a máquina. O computador funciona como um apoio no desenvolvimento das aulas.

São muitas as vantagens, como posso citar a seguir: Alunos motivados, professor motivado. O campo da interatividade se expande e não fica só em sala de aula. Vontade de aprender, vontade de ensinar. Aluno procura pelo conteúdo, aluno questiona o professor. Existe sempre um desafio, conversa entre aluno com aluno, conversa professor com professor e, principalmente, aluno com professor. A captação de informação conectado na internet é fabulosa você sabe, o aluno quer ver, quer conhecer, quer ir até aonde seu clic possa chegar, ele não quer parar, é um desafio a toda prova.

Os empecilhos por eles levantados: não ter os computadores na escola, a disciplina de informática, já existente, o apoio do Governo Estadual e Federal para dar maiores condições às escolas, e uma quebra de paradigmas de cada professor:

A capacitação dos professores é algo de relevada importância no momento. Os professores precisam se atualizar, fazer cursos. $O$ 
professor, neste caso, eu acredito não ser falta de vontade, mas sim de tempo, pois os professores têm a grande maioria uma carga horária de 40 horas em sala de aula e ainda toda atividade de preparo e correção de atividades em casa. Seria necessária uma dispensa, pelo menos em um turno para fazer os cursos. Mas acho sinceramente muito dificil acontecer isso na atualidade, pelas dificuldades encontradas nas escolas.

Por não possuir laboratório de informática na minha escola e pela dificuldade de locomoção de alunos para outro laboratório em período normal de aula, que dirá em período contrário.

\section{CONSIDERAÇÕES FINAIS}

Cremos que mais difícil do que equipar a escola com computadores é a tarefa de mudar concepções do ensinar e do aprender, da organização escolar com horários e currículos mais flexíveis, para que as tecnologias como os computadores se tornem mais eficazes na escola.

Formar profissionais aptos e dispostos a estar em constante aprendizagem é algo realmente importante em nossas instituições de ensino. Muito mais, ainda, quando falamos em formação de professores, visto que estes são formadores de novos cidadãos. Quando os alunos são motivados, desafiados, constantemente na busca de novas aprendizagens, as práticas dos professores também são diferenciadas, com isso, os profissionais terão uma probabilidade muito grande de se tornar profissionais reflexivos. Eles estarão sempre na busca de melhorar cada vez mais a sua prática.

As considerações aqui apresentadas dizem respeito aos cursos de capacitação, que servem para incentivar os professores a desmistificar o uso do computador na escola; também ressaltamos a importância de o Estado mudar a sua forma de ver os cursos de capacitação, dando apoio maior para que estes não se reduzam a treinamentos; enfatizamos que a formação para o uso das tecnologias seja algo presente na formação inicial e continuada de cada professor, mas sabemos que os cursos não são garantia de mudança, isso dependerá de todo um contexto maior em que a escola está inserida. 
Informática na educação: vantagens e empecilhos

\section{REFERÊNCIAS}

BELLONI, M. L. Educação a distância. Campinas: Autores Associados, 1999.

DEMO, P. Formação de formadores básicos. Em Aberto. Brasília, v. 11, n. 54, abr./jun. 1992.

MORAES, M. C. Paradigma educacional emergente. Campinas: Papirus, 1997.

MORAN, J.; MASETTO, M. T.; BEHRENS, M. A. Novas tecnologias e mediação pedagógica. Campinas: Papirus, 2000.

OLIVEIRA, R. Informática educativa: dos planos e discursos à sala de aula. Campinas: Papirus, 1997.

PROINFO. Bases do Programa Nacional de Informática na Educação. Disponível em: < http://www.proinfo.mec.gov.br/artigos.html $>$. Acesso em: 5 ago. 2000 .

VALENTE, J. A. (org.). O computador na sociedade do conhecimento. Campinas: Papirus, 1997.

Encaminhado em: 07/06

Aceito em: 11/06 